\title{
LA CAZA EN EL ARTE RUPESTRE DEL LEVANTE ESPAÑOL
}

\author{
M. ${ }^{a}$ Concepción Blasco Bosqued
}

A diferencia del arte paleolítico, en el del «Levante español, la escena es representada y desarrollada como elemento principal» (1), ya que el pintor está tratando de reproducir acontecimientos ocurridos en el quehacer diario; por ello, todos los objetos y seres «se sitúan ocupando un lugar previamente determinado por el artista en relación con los otros objetos que forman o integran la escena. Este sentido de relación entre objetos [y seres] es un aspecto nuevo en el arte hispano» (2); de manera que cuando se estudian aspectos parciales o temas concretos del arte levantino no pueden aislarse entre sí las figuras que forman parte de un mismo contexto.

Por ello, cuando acometimos el estudio de la figura humana en el Arte Rupestre Levantino (3), fue parte fundamental del trabajo la consideración de las escenas en las que el hombre formaba parte como principal protagonista. Entre todas las escenas merece especial mención las que se refieren a la actividad cinegética, tanto por su número como por su variedad, pues aun cuando "la datación absoluta, segura, sea imposible y los argumentos utilizados hasta ahora muy discutibles» (4), ya que carecemos de arte mobiliar que pueda servirnos de término comparativo y las industrias obtenidas en yacimientos próxmos a las pinturas no son en modo alguno concluyentes, pues junto a los microlitos de aspecto epipaleolítico encontrados, entre otros, en el Covacho de

(1) H. Kühn: Arte rupestre en Europa. Barcelona, 1957, pág. 71.

(2) Jordá, F.: Notas sobre Arte rupestre del Levante español. Caesaraugusta, 21-22. Zaragoza, 1963, pág. 10.

(3) El estudio de la figura humana en el Arte Rupestre Levantino fue el trabajo de Tesis de Licenciatura, leída en Zaragoza, en junio de 1968, bajo la dirección del Dr. Beltrán Martínez.

(4) Beltrán, A: Arte Rupestre Levantino. Zaragoza, 1968, pág. 56. 
Doña Clotilde, y en el de Val del Charco del Agua Amarga (5), en la mayor parte de los abrigos o no existen yacimientos, o no se conocen, o, incluso no pueden, en absoluto, ser contemporáneas a las pinturas (6). No obstante, nadie duda que el Arte Levantino fue creado por gentes cuya actividad primordial fue la caza, dado el elevadísimo número de escenas venatorias, aunque en muchas de ellas resulte difícil el determinar su verdadero significado no estando en este punto de acuerdo los distintos autores, ya que para unos tienen un valor fundamentalmente mágico, y otros piensan que su finalidad es exclusivamente narrativa (7).

El estudio detenido de las escenas de caza nos llevará a conocer datos tan importantes como son: el tipo de alimentación cárnica, el grado de evolución técnica del utillaje empleado, los diferentes sistemas para obtener las piezas e incluso el atuendo específico de quienes la practicaron. No obstante, antes de entrar en la enumeración de las escenas existentes, es necesario tener en cuenta que «la falta de figuras hace agrupar en escenas las que todavía se consrvan, falseando en muchos casos la composición original» (8), por lo que será preciso ponerse en guardia a la hora de determinar las escenas, y habrá que admitir solamente aquellas que se presentan como seguras.

Para el estudio de la caza hay que tener en cuenta dos aspectos fundamentales:

A) Las especies animales que son perseguidas y muertas.

B) Los sistemas y armas utilizados.

En cuanto a la fauna, consideramos sólo aquellas piezas que claramente forman parte de una escena de caza, mientras que haremos una

(5) Vid. Almagro, M.: Un nuevo grupo de pinturas rupestres en Albarracín: La. Cueva de Doña Clotilde. "Revista Teruel, núm. 2", Tomo I. Teruel, 1949.Beltrán, A.: La cueva del Charco del Agua Amarga y sus pinturas levantinas. Zaragoza, 1970, págs. 8 y siguientes.

(6) Como ejemplo basta citar los resultados obtenidos por E. Ripoll en sus excavaciones en el Covacho Ahumado de Santolea, donde aparecieron útiles de aspecto musteriense y restos óseos de "Cervus Elaphus» y "Equus Hydruntinus». Vid E. Ripoll: Los abrigos pintados de los alrededores de Santolea (Teruel). Barcelona, 1961, pág. 26. Resultado semejante obtuvo I. Barandiarán en las excavaciones realizadas en la Cerrada de Euduviges de Alacón. con quien colaboramos, y en las que se obtuvieron industrias asociadas a fauna igualmente musterienses.

(7) Vid. A. Beltrán, 4. Pág. 55.

(8) Maluquer, J.: La humanidad prehistórica. Segunda edición. Barcelona, 1971. Pág. 190. 
enumeración completa de todas aquellas armas y utensilios llevados por figuras humanas, excepción hecha de los personajes que están en una actividad no cazadora (guerra, recolección, etc.).

\section{REPERTORIO GENERAL}

Consideramos como indudables escenas de caza en las que existe relación inconfundible entre el hombre y el animal las siguientes:

Cogul: Tan sólo dos escenas de caza, y, en ambos casos, es una sola persona la que interviene. Se trata de las capturas de un ciervo y de un bóvido respectivamente, al parecer, el arma empleada en las dos ocasiones es el arco y las flechas. Existe una tercera escena, en la que un hombre parece huir de un animal de especie no identificada y que, con ciertas dudas, podríamos incluir en este tipo de escenas.

MAS DE RAMON D'EN BESSO: Un cazador en actitud de disparar hacia un bóvido, seguramente un toro.

VAL DEL Charco DEL agUa AMARga: Un arquero persiguiendo a una cabra ya herida por un venablo. Cazador corriendo tras un jabalí alcanzado por una flecha y al cual apunta un segundo arquero que le cierra el paso.

ABRIGo DEL ARQUERo: Cazador que se dirige hacia un macho cabrío herido por una flecha.

Covacho aHumado: Dos personajes relacionados con un toro. Cacería integrada por siete arqueros que corren detrás de otras tantas cabras, una de las cuales por su menor tamaño parece representar un animal joven.

Tía MonA: Extraña escena que parece relacionarse con la captura de una cierva y en la que intervienen varios arqueros.

ReCOlEctores: Dudosa representación de la caza de una cabra.

FRONTÓN DE LOS CÁprIDOS: Dos arqueros en actitud de disparar hacia una cierva.

ABRIgo DE LOS ToRicos: Cinco arqueros escondidos en una grieta de la roca, los cuales, sólo con ciertas dudas, pueden relacionarse con uno de los toros grandes del friso.

ABRIGo DE LOS ToRos: Cazador dirigiéndose a recuperar una cierva ya muerta, la cual ha sido representada en posición vertical, con la cabeza hacia abajo.

Abrigo de la Selva Pascual: Caza de un équido (caballo ?) a lazo, efectuada por un solo individuo. 
POLVORín: Una representación de captura de cabra (o quizá cierva) a lazo, llevada a cabo por un solo individuo. Cacería de dos ciervos en la que intervienen cinco arqueros. Cabra, al parecer, cogida por los cuernos por un solo hombre.

GALERÍa DEL ROURE: Cazador parado ante un ciervo. Arquero corriendo tras una cabra contra la que ya ha lanzado un venablo.

REMIGIA: Existen seis cacerías en las que forman parte varios arqueros; de ellas cuatro son de jabalíes, y están en un mismo panel; otra es de cabras montesas y la sexta de ciervos. Además, hay una escena con dos arqueros disparando contra un cáprido; otra, en la que un individuo dirige su arco hacia un bóvido, una más en la que un cazador dispara contra un mamífero no identificado y, por último, otras dos en las que sendos personajes lanzan sus flechas contra animales no determinados.

Cingle: Una figura disparando, al parecer, contra un bóvido. Otra escena en la que interviene una figura humana de pequeño tamaño que parece luchar, cuerpo a cuerpo, con un animal indeterminado. Sólo con ciertas dudas podemos incluir una tercera escena, que ha sido interpretada como el descabello de una cabra, lo cual supondría el acto final de una escena de caza.

Crvil: Escena de caza de un jabalí, aceptable sólo con ciertas dudas.

MAS D'EN Josep: Gran cacería de ciervos, en parte perdida, de la que se conservan sólo cuatro arqueros disparando contra seis ciervas, un ciervo macho, dos cervatillos y un cervato. Probablemente pueda darse también como escena de caza la representación de un arquero que corre tras una cierva.

ABrigo DEL CIERvo: Dos cacerías de «capra hispánica», Otro grupo formado por figuras parcialmente destruidas parece representar la captura de un cuadrúpedo no determinado por medio de una trampa. Existen otras dos escenas en las que se representan sendas figuras humanas junto a otros tantos animales, las cuales han sido interpretadas como lucha de hombre con animal.

ARAÑA: Fase final de la cacería de una cabra.

ToRTosilla: Figura de cazador parado ante un rumiante.

CUEva DE LA VIEJA: Cuatro escenas, en cada una de las cuales interviene un solo arquero que se enfrenta a un ciervo y dispara contra él.

ABRIgo DE LOS CHIvos: Arquero disparando contra un grupo de cuatro cabras y una cierva.

ABRIgo DE SAUTUOLA: Una cacería de cabras. 
SOLANA DE LAS COVACHAS: Grupo de figuras humanas disparando flechas contra animales indeterminados.

\section{ESPECIES CAZADAS}

Como hemos podido ver, las especies cazadas son muy poco variadas, ya que sólo podemos asegurar la existencia de cazadores dirigiendo sus disparos contra: cápridos, cérvidos, jabalíes, bóvidos (seguramente toros) y équidos, además de una serie de cuadrúpedos no identificados por el mal estado de su conservación, pero es posible que pertenezcan

una de las especies antes citadas. Es preciso recordar que «a pesar de haberse señalado la presencia de figuras típicas de la fauna diluvial los ejemplos que $\mathrm{H}$. Breuil y $\mathrm{H}$. Obermaier sostienen son siempre dudosos. Lo seguro es observar animales representados propios de la fauna actual» (9), lo que nos lleva a incluir este arte dentro de una cronología post-paleolítica.

a) CÁPRIDOS: Podemos asegurar la presencia de cacerías de esta especie animal en: Covacho Ahumado, Cueva Remigia, Abrigo del Ciervo del Barranco de Dos Aguas (dos escenas), Cueva de la Araña, Abrigo de los Ciervos de Nerpio y Abrigo Sautuola, lo que supone un total de siete escenas a las que hay que añadir otras ocho en las que sólo un hombre, o a lo sumo dos, disparan su flecha contra uno de estos animales o lo atrapan de alguna otra forma.

Esta suma de quince escenas de caza de cápridos, además de otras muchas perdidas actualmente, convierten a esta especie en una de las presas más frecuentes, hecho que posiblemente se deba a dos causas: su abundancia en estos parajes y el ser muy codiciada no sólo como productora de carne, sino también de leche. Por otra parte, es preciso advertir que la presencia de cabras está constatada, sino en todos los abrigos, al menos sí en todo el área del Arte Rupestre Levantino.

Parece que el sistema utilizado en las cacerias fue el ojeo, método que no difiere del empleado para la captura de otras especies y que todavía hoy se practica sin grandes variaciones. La primera fase de este sistema la tenemos representada en el Covacho Ahumado, donde «cuatro animales huyen de la furiosa persecución de varios cazadores que disparan sus dardos en plena carrera. El grupo de avanzada lo

(9) Almagro, M.: Las pinturas rupestres levantinas. Madrid, 1954, pág. 18. 
forman cuatro reses adultas y, entre ellas, una cabrita más joven» (10). El conjunto se desplaza de derecha a izquierda y de arriba hacia abajo, dando la sensación de que las reses han sido obligadas a encaminarse al fondo del barranco.

Por otra parte, la fase final del ojeo está perfectamente representada en las dos escenas del Abrigo del Ciervo, en las que tres arqueros rodean a una "capra hispánica» herida por dos flechas y se disponen a lanzarse sobre ella (11) (Lám. I).
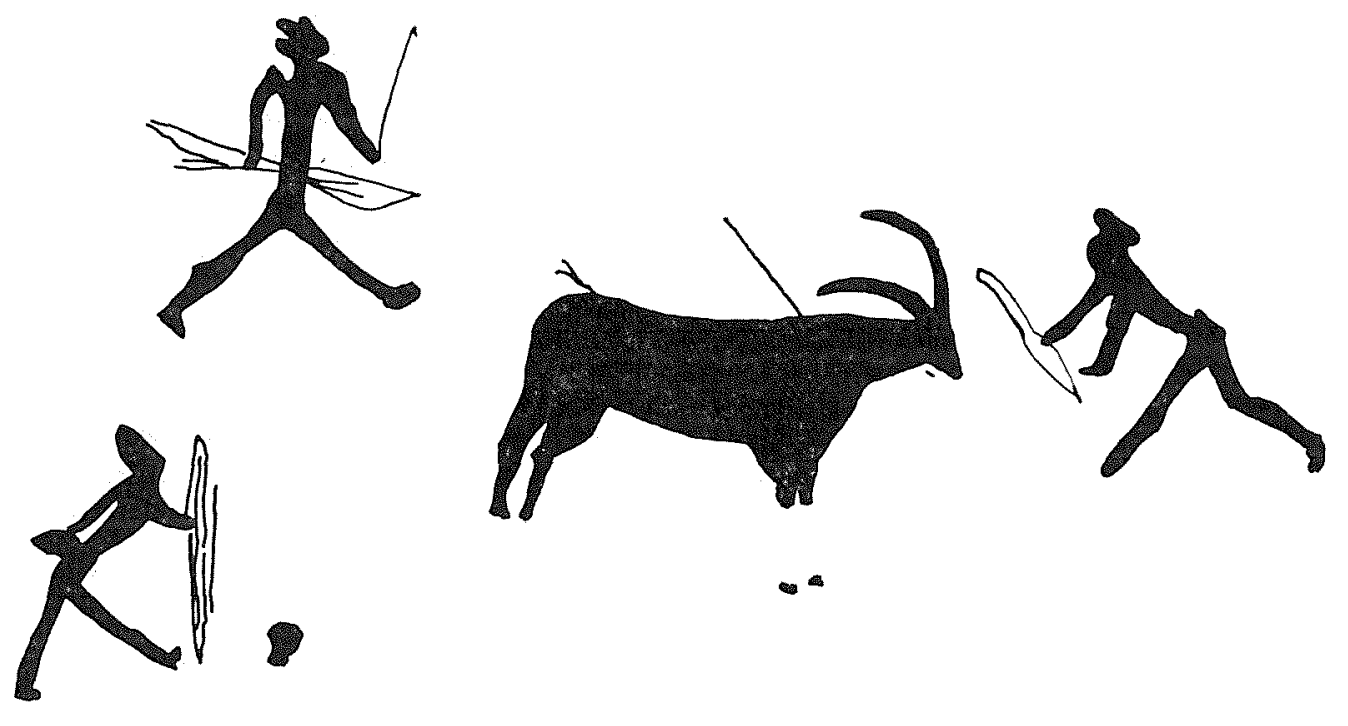

LAMINA I

Cacería de «capra hispanica» representada en el Abrigo del Ciervo del Barranco de Dos Aguas (según F. Jordá).

Esta misma etapa final del ojeo se encuentra también representada en la Cueva de la Araña, en una de las escenas más completas de todo el Arte Levantino, donde puede verse la entrada de las reses en la celada, pues «las piezas parecen dirigirse a la garganta del barranco,

(10) Ortego, T.: Nuevas estaciones de Arte rupestre aragonés: "El Mortero" y "Cerro Felio", en el término de Alacón (Teruel). Archivo Español de Arqueología, T. XXI. Madrid, 1948, pág. 18.

(11) Jordá, F., y Alcacer, J.: Las pinturas rupestres de Dos Aguas (Valencia). Valencia, 1951, vid., pág. 19. 
donde la altiplanicie confluye en un embudo, allí donde aguardarán los cazadores» (12) (lámina II).
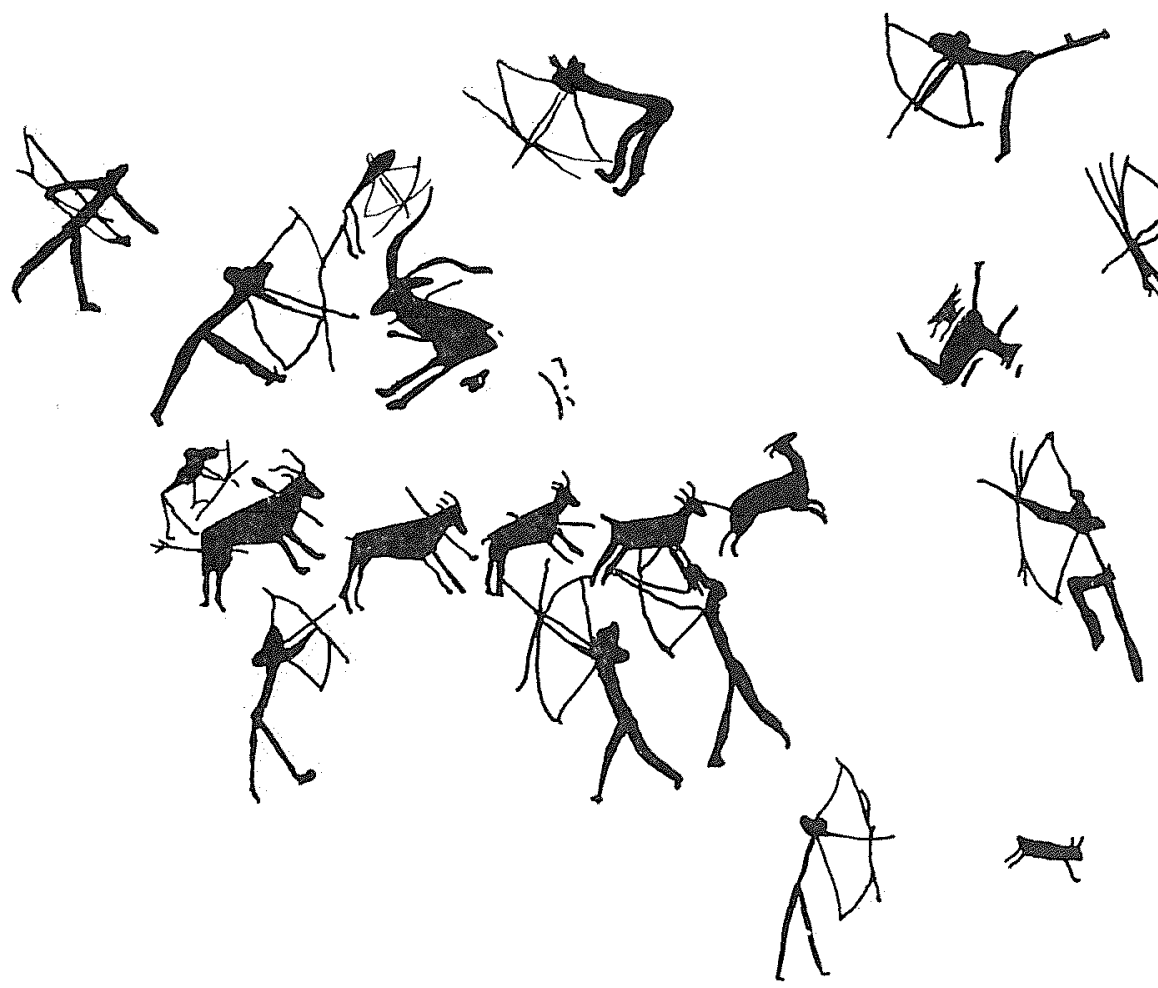

LAMINA II

Cacería de cabras representada en la Cueva de la Araña (según Hernández Pacheco).

El hecho de que las reses deben estar entrando en el desfiladero parece indicarse por su disposición en fila. Lo más espectacular de la escena es el elevado número de cazadores que intervienen, doce en total, así como la cantidad de reses objeto de sus disparos, las cuales suman nueve. Es interesante observar que dos de los cazadores son de menor tamaño, lo que puede indicar que se trata de dos individuos jóvenes y por eso resulta lógica su posición retrasada.

(12) Hernández-Pacheco, E.: Las pinturas prehistóricas de las cuevas de la Araña (Valencia). Evolución del Arte rupuestre en España. Madrid, 1924, páginas 64-65. 
Las demás escenas enumeradas anteriormente están más incompletas y, por tanto, resultan más confusas. Unicamente hay que destacar el hecho de que uno de los personajes que interviene en la cacería de cabras del Abrigo Sautuola lleva sobre la cabeza una «especie de gorro con orejas de animal tal como se ven a menudo en Alpera, quizá -utilizado- como disfraz de caza» (13). Este atuendo lo vemos también en la Cueva Remigia, donde otro cazador de cabra se cubre con un tocado animal. Es muy posible que este tipo de gorro no tuviera finalidad ornamental, sino que exclusivamente se empleara como un ardid de caza con el fin de atraer a las piezas, tanto en acciones colectivas como en las individuales, no siendo en absoluto privativo de la caza de cápridos, pues, como se verá, aparece empleado también en la captura de otras especies.
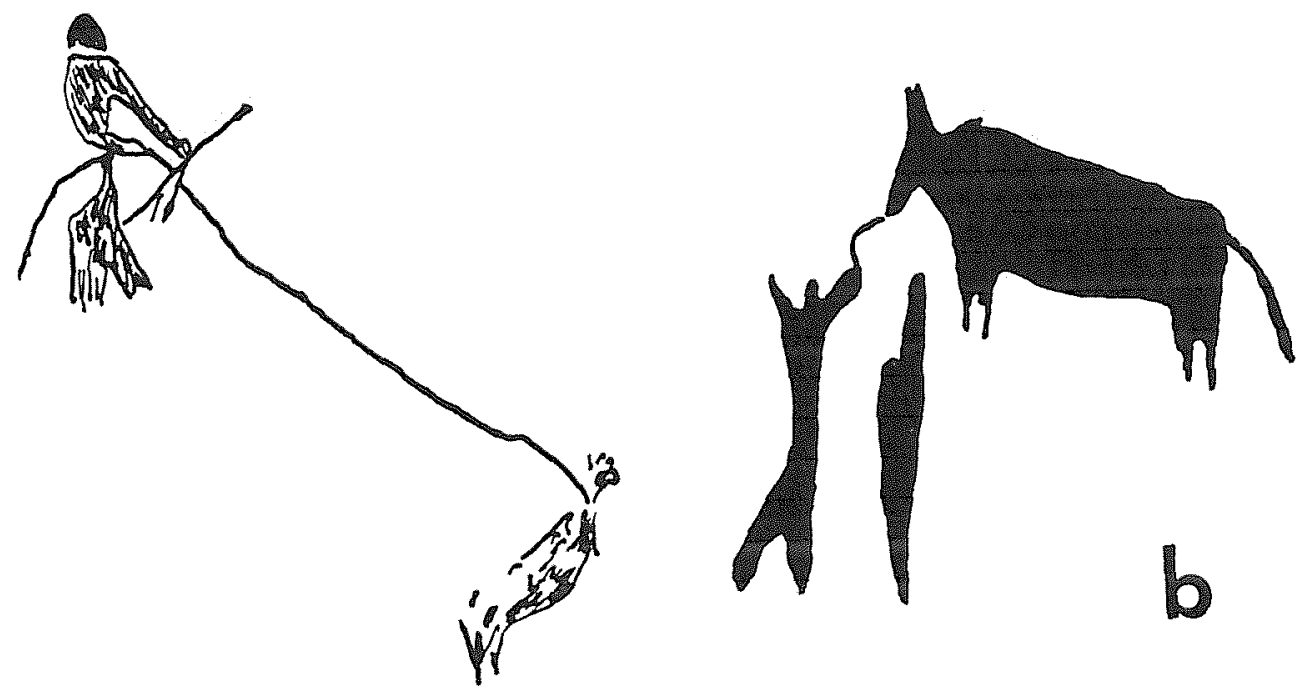

LAMINA III

Ecenas de caza a lazo. a) De cierva, representada en la Cueva del Polvorín (según S. Vilaseca). b) De équido, representada en el Abrigo de Selva Pascuala (según Almagro y G.a Bellido).

(13) García Guinea, M. A.: Le nouveaux et important foyer de peintures levantines à Nerpio (Albacete, Espagne). Bulletin de la Société Préhistorique de l'Ariège, Tomo XVIII. Tarascon-sur-l'Ariège, 1963, pág. 22. 
Las escenas en las que interviene un solo individuo, éste dispara, por medio de un arco, dardos contra el animal, con excepción de una representación del Abrigo del Polvorín, en la que el cazador, pese a llevar arco y flechas en una de sus manos, se ha valido de una cuerda para aprisionar a la cabra (14) (lámina III a). Un paralelo semejante parece existir en el Abrigo de los Recolectores, aunque en este caso la escena resulta mucho más confusa (15).

Es posible que una vez cobradas las piezas malheridas, éstas fueran muertas con la ayuda de algún arma cortante, ejecutándose una especie de descabello según parece desprenderse de una escena algo confusa del Abrigo IV del Cingle, en la que se ve a un individuo con una especie de puñal en la mano, en actitud de clavarlo a una cabra (16) (lámina IV).

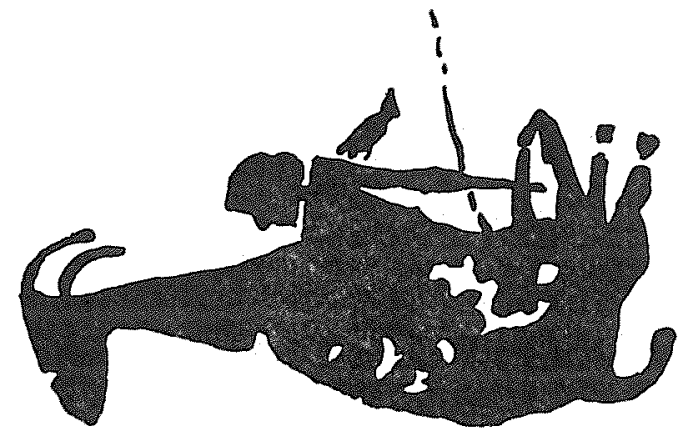

LAMINA IV

Escena de ¿descabello? representada en el Cingle (según E. Ripoll).

Respecto a las armas utilizadas, ya ha quedado dicho que normalmente se emplea el arco y las flechas, excepción hecha de los dos casos de caza con lazo; además, algunos autores han querido ver, siempre en casos no muy claros, el empleo de una especie de jabalina, pero dicha interpretación resulta algo aventurada.

(14) Vilaseca, S.: Las pinturas rupestres del Polvorin (Puebla de Benifazá, provincia de Castellón). Informes y Memorias de la Comisaria General de Excavaciones Arqueológicas, núm. 17. Madrid, 1947, pág. 20.

(15) Beltrán, A.: Peintures rupestres du Levant de "El Abrigo de los Recolectores", dans le ravin de "El Mortero" (Alacón, Teruel, España). "Bulletin de la Société Préhistorique de l'Ariège», Tomo XVI-XVII. Tarascon-sur-1Ariège, 19611962, pág. 12, de tirada aparte.

(16) Ripoll, E.: Pinturas rupestres de la Gasulla (Castellón). Monografías de arte rupestre, arte levantino, núm. 2. Barcelona, 1963, pág. 28. 
b) CÉRvidos: La frecuencia de escenas de caza de esta especie es semejante a la de cápridos, pues existen un total de cinco cacerías representadas en los siguientes abrigos: Tía Mona, Frontón de los Cápridos, El Polvorín, Cueva dels Cavalls y Cueva Remigia; además, en nueve ocasiones encontramos arqueros disparando contra este tipo de animales.

El sistema de caza es el empleado en la captura de cápridos, es decir, el ojeo, del cual tenemos un extraordinario ejemplo para esta especie en la Cueva dels Cavalls, donde «a la izquierda se ven cuatro cazadores, uno encima del otro; a la derecha, una manada de ciervos (diez en total) en carrera emprendida en dirección a los tiradores que los cubren los proyectiles.

Hay que suponer, por lo menos hipotéticamente, que detrás de estos animales existía un grupo de ojeadores, probablemente también armados, pues así lo da a entender la presencia de algunas flechas en los cuartos traseros de los cérvidos" (17).

No obstante esta descripción de Obermaier y Wernert al publicar el abrigo, es inexacta, porque se refiere sólo a la parte izquierda de la escena y ello ha dado pie a que este conjunto - uno de los más conocidos de la pintura ruepstre levantina - se reproduzca de forma parcial, pero esta errónea interpretación se debe a la existencia de una gran caída estalagmítica que divide el conjunto en dos. No obstante, el error fue rectificado por A. Beltrán, quien publicó el calco de Benítez Mellado completo, y en el cual se advierte perfectamente la presencia de un grupo de ojeadores que corren tras los ciervos y que, sin duda, son quienes han disparado las flechas a las que hacen referencia Obermaier y Wernert (18).

Dentro de esta escena resulta interesante advertir la presencia de dos cervatillos, diferenciados de las reses adultas no sólo por su menor tamaño, sino también por tener el cuerpo manchado por una serie de puntos que parecen indicar la diferencia de piel. Estos animales jóvenes se encuentran situados en el centro de la manada, arropados por los de mayor tamaño. Además se han diferenciado también dos ciervos machos provistos de gran cornamenta, mientras que las hembras que carecen de ella.

En el Covacho de la Tía Mona resulta sorprendente la presencia

(17) Obermaier, H., y Wernert, P.: Las pinturas rupestres del Barranco de Valltorta (Castellón). Madrid, 1919, pág. 64.

(18) Beltrán, A., 4. Vid., fig. 124. 
de un extraño personaje sentado en una especie de parihuelas entre los arqueros que asisten a la cacería de una cierva; no obstante, sólo T. Ortego incluye a dicho personaje dentro de la citada escena (19); en cualquier caso no encontramos pararelos semejantes en otros abrigos levantinos, y sería aventurado afirmar la participación de personajes de alto rango en las cacerías, transportados en literas.

Como en el caso de la caza de cabras, existen en la Cueva de la Vieja arqueros disparando contra ciervos, tocados con gorros de orejeras que parecen cabezas zoomorfas y que, como ya hemos apuntado antes, hay que interpretarlos como un ardid. Mucho más frecuentes son los tocados de plumas entre los cazadores tal como puede observarse en el personaje del Abrigo de Mas d'en Josep, que persigue a dos grandes ciervos, pero dichos tocados no son privativos de esta actividad, pues los encontramos adornando también cabezas de mujeres, así como de personajes masculinos dedicados a otras actividades tales como la guerra, por eso resultaría aventurado interpretarlos en el mismo sentido que los gorros animales.

Por último, cabe señalar una curiosa escena reproducida en el Abrigo de las Caídas del Salbime, posiblemente relacionada con la caza, donde se ve una cierva que corre veloz tras un hombre que posiblemente trató de atacarla, sin embargo, ni el personaje va armado ni el animal presenta dardos clavados en su cuerpo.

Las armas utilizadas para la obtención de esta especie que comentamos son, sin excepción, el arco y las flechas. Por otra parte, al igual que los cápridos, los cérvidos aparecen representados en todo el área por la que se extiende la Pintura Rupestre Levantina.

c) JABALfES: Son mucho menos frecuentes que las dos especies anteriormente citadas, y aparecen representados sólo en dos abrigos de la zona del Maestrazgo: Cueva Remigia y Cueva del Civil y en Val del Charco del Agua Amarga.

Las más bellas representaciones de caza de jabalíes las tenemos en cuatro escenas existentes en la Cueva Remigia, reproducidas en un mismo panel y superpuestas entre sí (lámina V). En ellas puede observarse una serie de arqueros lanzados a la carrera tras los animales que huyen veloces; algunos de ellos están heridos por múltiples vena. blos y uno parece ya muerto, pues se ha representado apoyado sobre

(19) Ortego, T., 10. Pág. 31. Sin embargo, ni Almagro, M.: Las pinturas rupestres del Bajo Aragón, "Prehistoria del Bajo Aragón» (Zaragoza, 1956, pág. 80); ni Beltrán, A., 15 (pág. 29), lo consideran como perteneciente a la cacería. 
el dorso y con las patas hacia arriba. Destaca en este conjunto la perfecta ejecución de los animales realizada con todo lujo de detalles.

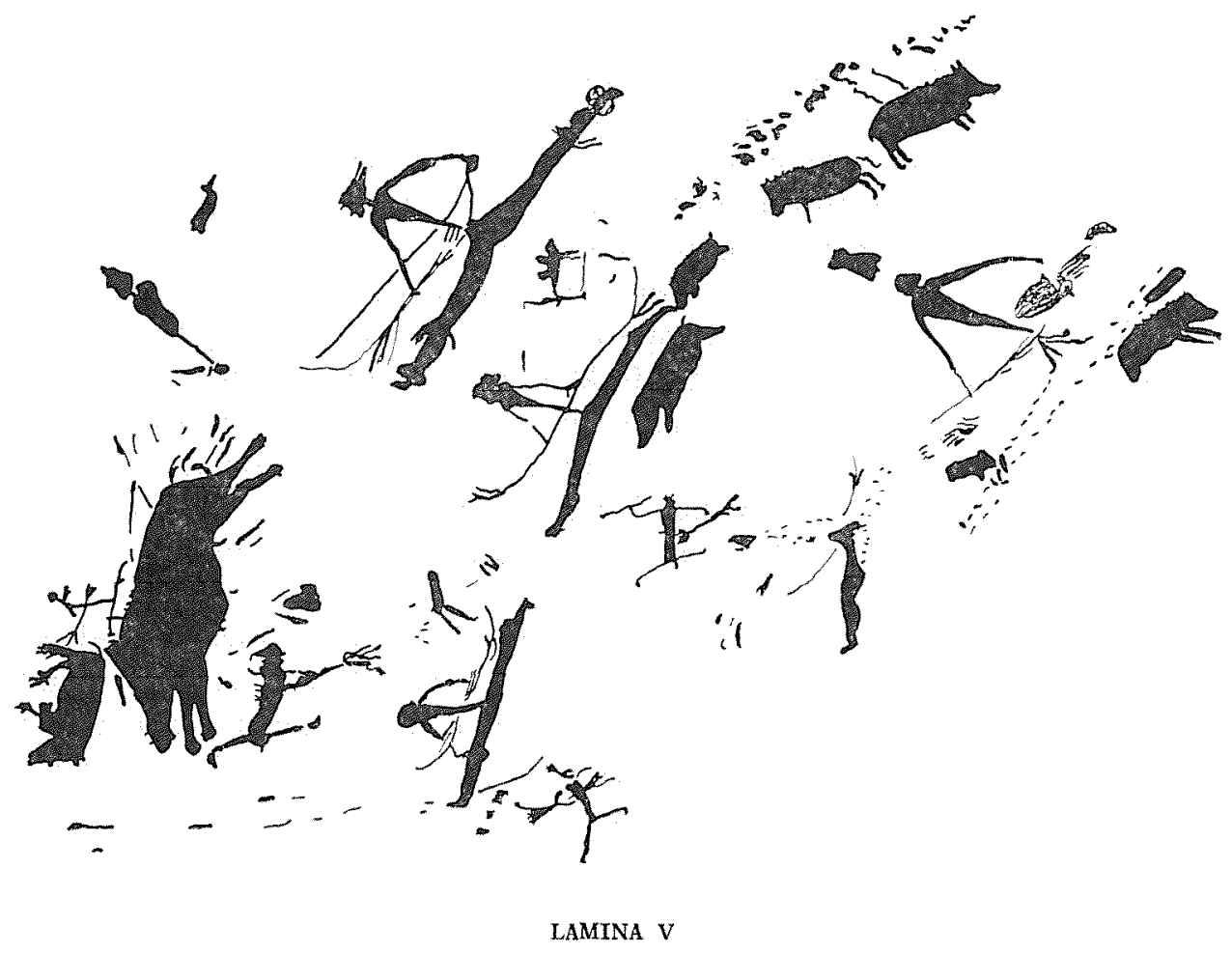

Cacerías de jabalies representadas en la Cueva Remigia (según J. B. Poscar).

En Val del Charco, la escena es muy similar, aunque sólo un arquero corre - con seguridad - tras el jabalí. Sin embargo, es posible que otros dos cazadores más intervengan en la recuperación de la pieza herida (20).

Muy problemática resulta la escena del Civil descrita por Obermaier al dar a conocer este abrigo, y que él mismo apuntó como muy poco segura (21).

No tenemos testimonio de que el sistema de caza de jabalíes fuera también el ojeo, pues en ningún caso se nos representan los arqueros ante las piezas, ya que sólo aparecen corriendo tras ellas. Si nos atene-

(20) Beltrán, A., 5. Pág. 39.

(21) Obermaire, H., y Wernert, P., 17. Pág. 118. 
mos a los restos pintados hay que pensar que las únicas armas empleadas en su captura fueron el arco y las flechas.

d) Bóvidos: Pese a que la especie está ampliamente representada en numerosos abrigos repartidos por toda el área de la Pintura Levantina, las escenas de caza de este tipo de animales son muy escasas - cuatro en total-y en algún caso problemática.

Las dos únicas representaciones que parecen más seguras: la del Abrigo de los Toricos del Prado del Navazo y la del Mas de Ramón d'en Besso, llaman la atención por lo diminuto y esquemático de los cazadores frente al gran amaño y naturalismo de las reses, pero en ninguno de los dos casos parece existir duda de que el objeto del disparo de los arqueros sean los bóvidos. Sin embargo, en el caso del Abrigo de los Toricos del Prado del Navazo el hecho de que las figuras humanas sean de color blanco y los bóvidos negros, hace pensar que sea una composición realizada en dos fases: a la primera de ella pertenecerían los bóvidos, y posteriormente se añadirían los arqueros (lámina VI).

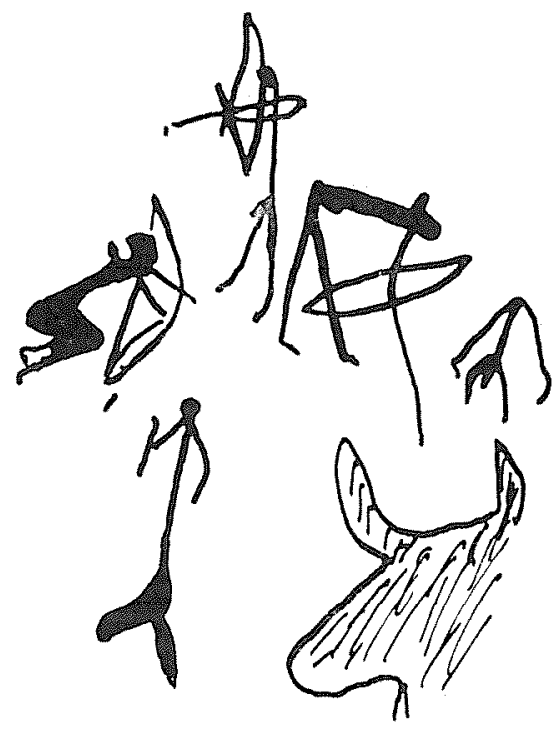

LAMINA VI

Cacería de bóvidos, del Abrigo de los Toricos del Prado del Navazo (según M. Almagro).

En la Cueva Remigia nos encontramos entre una escena semejante a la de las Caídas del Saldime, pues claramente se observa la veloz 
huida de un arquero ante la embestida de un toro; aunque no es seguro que esta escena sea la consecuencia de un intento de caza por parte del personaje, el hecho de que éste vaya armado y, sobre todo, el venablo que tiene clavado el animal en su cuerpo, hacen pensar en esta posibilidad.

La escena del Covacho Ahumado, apuntada por T. Ortego como caza de bóvido, nos parece muy poco probable: en efecto, se trata de figuras muy perdidas que no hemos conseguido identificar en el propio abrigo y que no aparecen en el calco publicado por M. Almagro (22).

e) Eouidos: No es especie muy frecuente ni aislada ni formando composición con figuras humanas; dejando aparte las posibles escenas de doma y monta existentes en la Cueva de Doña Clotilde y en el Cingle de la Mola Remigia, que no entran dentro del tema que proponemos, existen tres representaciones relacionadas con la caza de équidos.

En la Cueva de la Araña aparece un gran équido, seguramente un caballo, que parece estar muerto por las heridas de tres flechas que tiene clavadas en el vientre, ya que ha sido representado en posición vertical, con la cabeza y las patas delanteras hacia abajo en el momento de precipitarse en el vacío.

Como escenas de caza propiamente dichas, existen sendos ejemplos en los abrigos de Selva Pascuala y de los Borriquitos, respectivamente. El primero ha venido siendo considerada tradicionalmente como un caso de doma, no obstante, A. Beltrán rectificó esta creencia al considerarlo «como una escena de caza con lazo de la que no faltan ejemplos en el Arte Levantino» (23) (lám. III b), comparándola con la escena del Polvorín que hemos mencionado al referirnos a los cápridos.

La escena de los Borriquitos resulta mucho más confusa; según Almagro, parece reproducir la caza de un équido en la que intervienen dos personajes, uno armado con un objeto circular y otro provisto de una larga lanza (24). Por su parte, Ortego opina que se ha tratado de representar la captura de un asno utilizando una «raíz elástica de sabina" manejada por dos hombres (25); si aceptamos esta última versión, estaremos en presencia de una forma de caza semejante a la representada en el Abrigo de la Selva Pascuala y habría que pensar que

(22) Almagro, M., 19. Figs. 45 y 46.

(23) Beltrán, A.: Sobre la pintura rupestre levantina de un caballo cazado a lazo, del abrigo de "Selva Pascuala", de Villar del Humo (Cuenca). "Miscelánea ofrecida al Iltmo. Sr. D. José María Lacarra y de Miguel». Zaragoza, 1968, pág. 83.

(24) Almagro, M., 19. Pág. 75.

(25) Ortego, T., 10. Pág. 7. 
el sistema de captura no es igual para todas las especies, sino que se adapta a las características de cada una, utizándose normalmente en el caso de los équidos el lazo $u$ otro instrumento de fibra, siendo esporádico el empleo de flechas.

f) Especies no IDENTIFICADAs: Considerando dentro de este apartado todas aquellas escenas en las que el objeto de caza son animales cuya especie no ha podido determinarse bien porque se trata de figuras mal conservadas, bien por la imprecisión del diseño en el que están ausentes aquellos rasgos característicos que facilitan la identificación. Por una de estas dos causas se han producido interpretaciones erróneas, como en el caso del animal de la Cueva del Tortosilla, en el que Breuil y Cabré vieron un rebeco (26), o en uno de los de la Cueva Remigia que el mismo Breuil identificó como un alce (27). Sin embargo, es importante anotar aquí que tales interpretaciones de Breuil ante casos no muy claros se deben, en gran parte. al deseo del gran prehistoriador francés de tener justificaciones que le permitieran defender una cronología paleolítica del Arte Rupestre Levantino, basándose en la existencia de especies extinguidas en aquellas latitudes en una época postglaciar.

Entre las representaciones de cacerías de animales de imposible identificación, debido a su parcial conservación, hay que destacar dos: la existente en el Abrigo del Ciervo del Barranco de Dos Aguas y la reproducida en La Solana de Las Covachas. En la primera se representan tres figuras humanas portando arco y flechas y bajo ellas "hay un trazo filiforme, que, siguiendo una línea sinuosa se entrecruza formando tres espacios que interpretamos como una trampa de caza. El trazo presenta tres abultamientos que podrían ser considerados como nudos o uniones de la cuerda que aquel puede representar. Dentro del espacio superior se encuentra una mancha de color sin forma definida, posiblemente los restos o fragmentos de lo que debió de ser la presa» (28) (lámina VII a). Se trata, pues, de la captura de un animal valiéndose de una trampa, pero lo imparcial de la conservación nos impide conocer algunos detalles tales como si el animal había sido previamente herido por flechas o qué sistema pudo utilizarse para hacerle

(26) Cabré, J.: El arte rupestre en España. Madrid, 1915, págs. 205-206.

(27) Porcar, J. B.; Obermaier, H., y Breuil, H.: Excavaciones en la Cueva Remigia (Castellón). «Memorias de la Junta Superior del Tesoro Artístico. Madrid, 1935 , pág. 31 .

(28) Jordá, F., y Alcacer, J., 11. Pág. 13. 

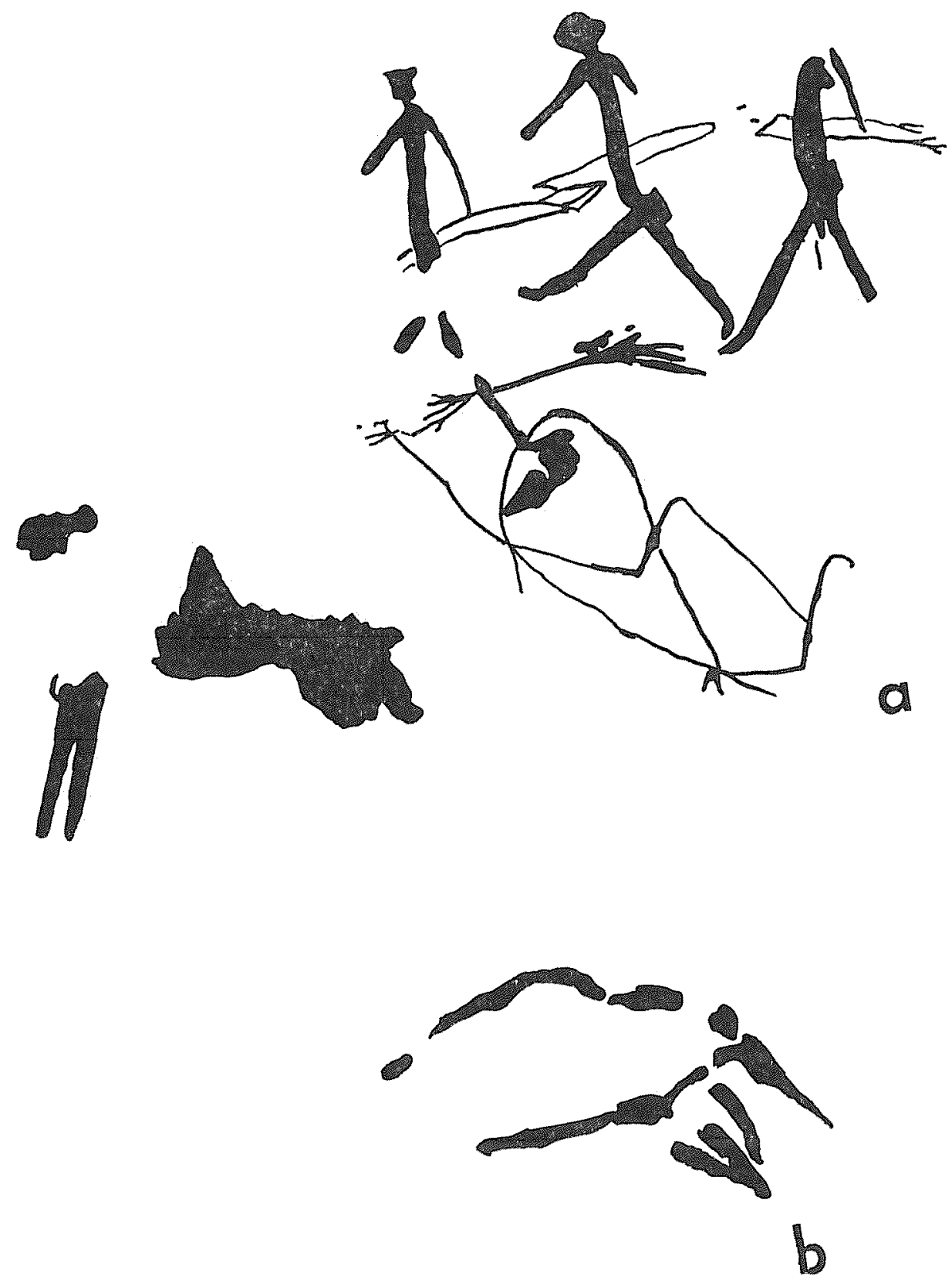

LAMINA VII

Representación de trampas: a) Caza de cuadrúpedo, utilizando posible trampa, representada en el Abrigo del Ciervo del Barranco de Dos aguas (según F. Jordá). b) Posible trampa para cazar pájaros reproducida en el Cinto de la Ventana del mismo Barranco de Dos Aguas. (según F. Jordá). 
caer en la trampa; por otra parte, al tratarse de la única escena de caza con trampa reproducida en los frisos levantinos conocidos resulta imposible establecer comparaciones.

En la Solana de Las Covachas nos hallamos en presencia de otra cacería de cuadrúpedos en la que los arqueros participantes parece que se sirven del sistema del ojeo ayudándose con tocados en forma de cabeza de animal, al igual que hemos comprobado en otros ejemplos.

En el Abrigo VI del Cingle de la Mola Remigia puede observarse a un personaje cerca de un animal de estilo algo esquemático, esta escena ha sido interpretada por Ripoll como la lucha de un hombre con un animal y de la que tenemos un paralelo en las dos escenas reproducidas en el Abrigo del Ciervo del Barranco de Dos Aguas, las cuales, en opinión de Jordá, parecen tener carácter mágico dada la voluntaria destrucción de la zona de las cabezas al haber desaparecido tal sentido mágico (29).

Resta, por último, reseñar una escena del abrigo de Cogul en la que un hombre huye de un animal no identificado tal como hemos visto ya en la Cueva Remigia y en el Abrigo de las Caídas del Salbime.

\section{INGENIOS DE CAZA}

a) ARMas: De lo dicho anteriormente se desprende que, a excepción de algunas salvedades, las armas utilizadas para la caza son las mismas que se empleaban para la guerra, es decir, el arco y la flecha, por ello cabe suponer que lo mismo que "la cultura central se halla especialmente articulada en el arco y la flecha» (30), para estas gentes dichos elementos eran también el armamento básico.

Normalmente los arqueros caminan llevando el arco y las flechas en la misma mano, la derecha, y sólo en alguna ocasión sostienen con la izquierda una flecha mientras que transportan el resto de las armas con la derecha. Cuando disparan, lo hacen sujetando el arco y el manojo de flechas con la mano izquierda utilizando la derecha para sustentar la cuerda del arco y la emplumadura del proyectil (lámina VIII a).

(29) Jordá, F., y Alcacer, J., 11. Pág. 20.

(30) Barandiarán, J. M.: Breve historia del hombre primitivo. Anuario de Eusko Folklore», Tomo XI. 1931, pág. 136. 

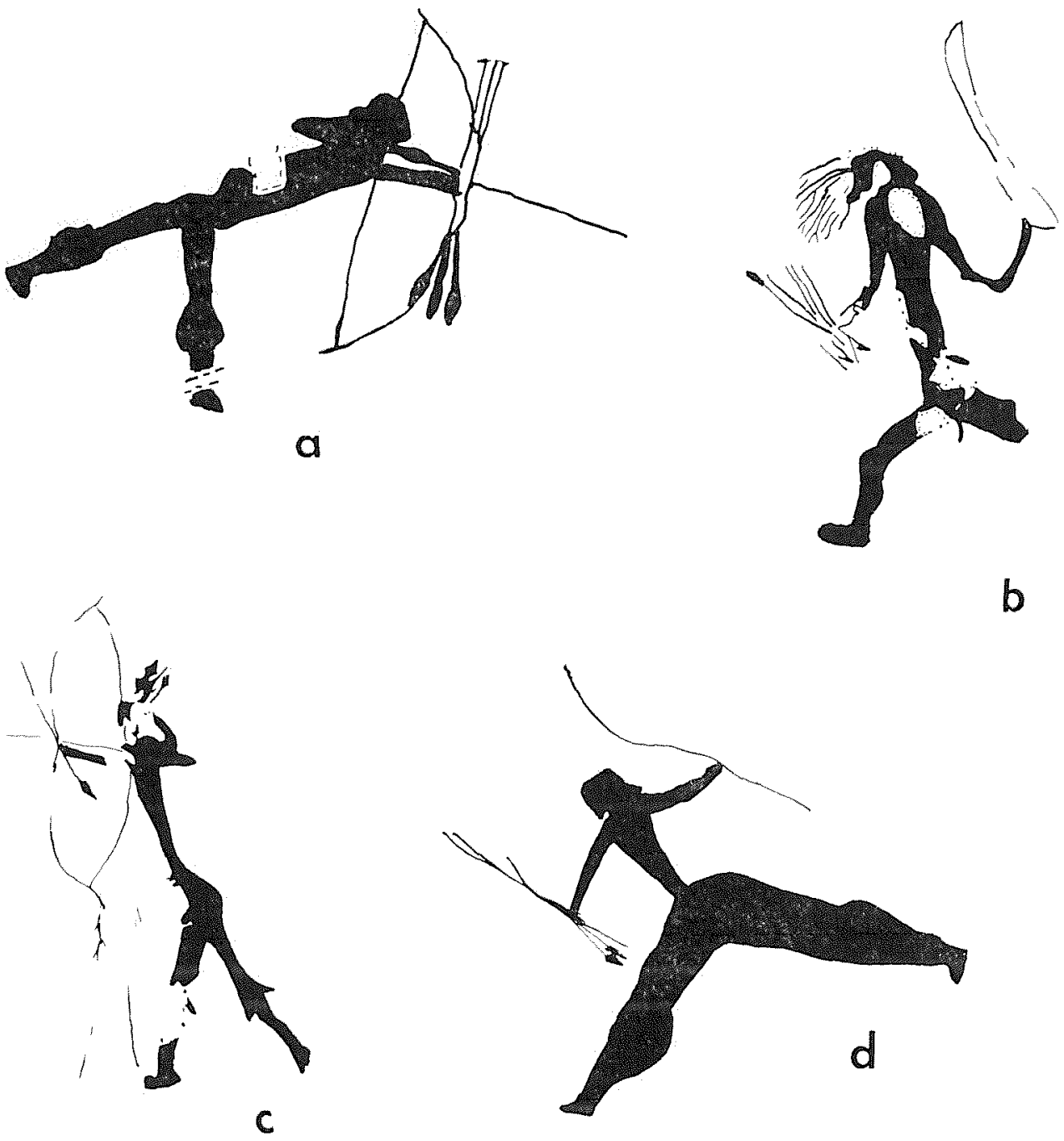

b

C

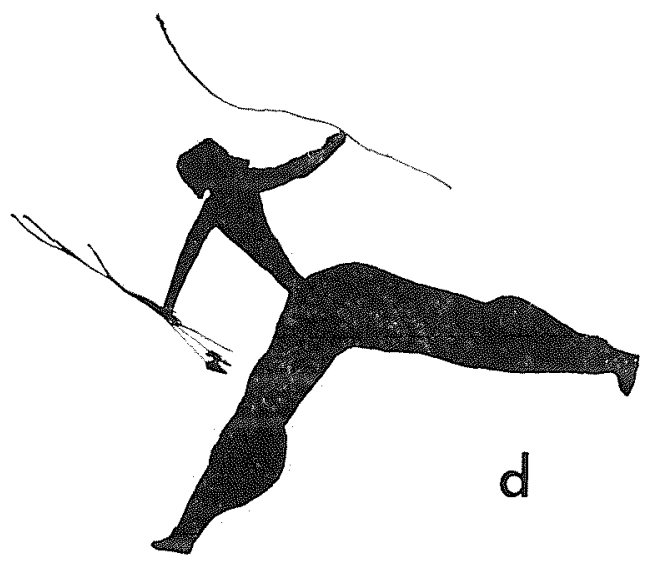

LAMINA VIII

Distintos tipos de arco: a) Sencillo de curvatura normal. b) Sencillo y aplanado en el centro. c) De triple curva. d) De doble curva.

El arco se haya representado unas seiscientas veces, muchas de ellas sin poderse precisar a qué tipo pertenece, ya que se reduce a un pequeño trazo. La cuerda está representada en sólo cincuenta ocasiones, aunque suponemos que muchas veces habrá desaparecido. 
Sólo en algunas ocasiones contamos, afortunamente, con excepciones en las que se dibuja el armamento con asombrosa minuciosidad y nos permite distinguir diferentes tipos. No obstante, siempre hay detalles que la pintura no puede expresarnos y que la falta de hallazgos arqueológicos nos impide conocer, como son la materia prima, el tipo de cuerda o la sección del arco.

Parece lógico que la materia empleada en la fabricación de arcos fuera la madera, aunque no se puede descartar la posibilidad de que algunas veces se hicieran con otra materia vegetal o con hueso. La cuer$\mathrm{da}$, seguramente, se confeccionaría igualmente con materia vegetal o con fibra animal.

«La sección importa, porque indica si la madera ha sufrido transformación» (31), pero por el momento es imposible conocer si los arcos eran de sección redonda o, por el contrario, habían sido aplanados con el fin de obtener mayor elasticidad.

Con respecto a la forma, podemos comprobar el empleo de dos tipos: a) arco simple, y b) arco compuesto. El arco simple está fabricado con un solo segmento, y es, sin duda, el más abundante en las representaciones del Arte Levantino (lámina VIII a); presenta normalmente una curvatura normal, aunque existe una variante de tamaño pequeño, que muestra una zona aplanada en el centro semejante al arco del violín; este tipo lo encontramos representado en la Cueva de la Vieja, en manos de los personajes denominados "pieles rojas" (32) y en el Abrigo del Ciervo del Barranco de Dos Aguas, donde es transportado por un cazador de cabras (lámina VIII b).

El arco compuesto del que es característico el ser reflejo tiene la parte central impregnada de una sustancia grasa que le permite ceder mucho más a la hora del disparo (33). En el arte levantino lo vemos en diferentes variantes: ¿con doble?, triple o incluso múltiple curva; de ellos el más frecuente es el de triple curva o asiático (lámina VIII c), del que encontramos hasta treinta representaciones, en su mayoría en la Cueva de la Vieja de Alpera y en los abrigos de Minateda. Para Lhote «la presencia en los frescos de España oriental no sólo del arco ordinario simple. sino del arco de triple curvatura, llamado asiático, no

(31) Grottanelli, Vinigi: L'uomo e la civilitá. En T. II, de Le opere dell'uomo. Milán, 1965, pág. 178.

(32) Breuil, H., y Obermaier, A.: Les premiers travaux de l'Institut de Paléontologie Humanie. Vol. II. Travaux sur les peintures rupestres d'Espagne. 2 Alpera (Albacete). "L'Anthropologie», Tomo XXIII. París, 1912.

(33) Grottanelli, 31. Pág. 182. 
sabría explicarse sin una relación entre las dos regiones [el Tassilli y el Levante español], de la que es prematuro precisar las condiciones y el tiempo» (34).
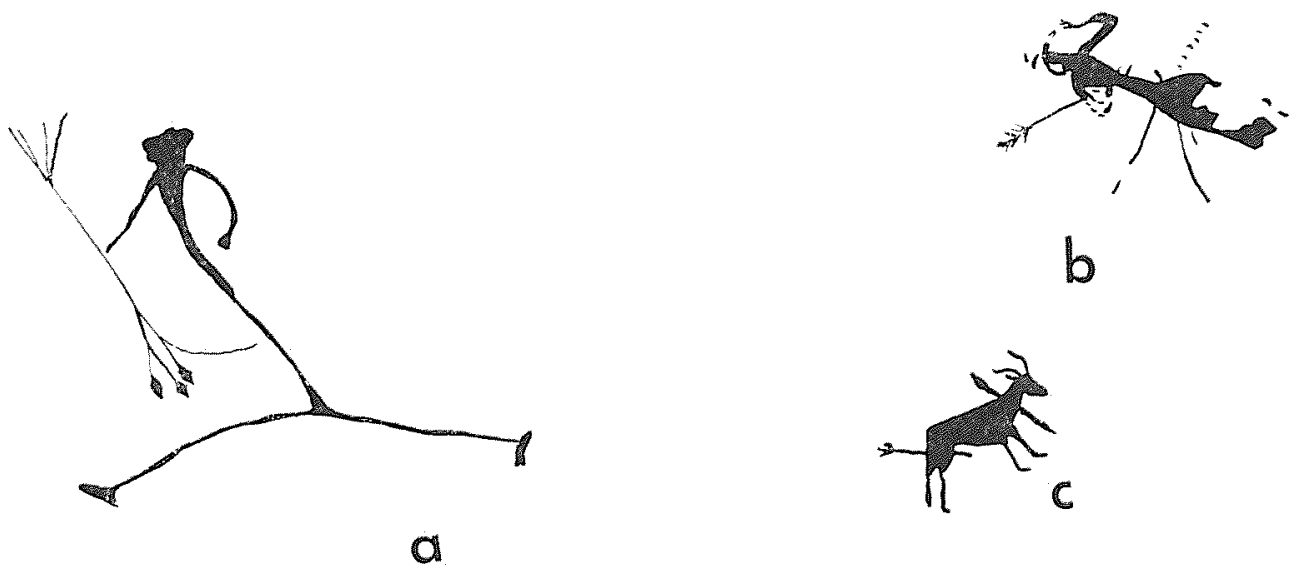

b
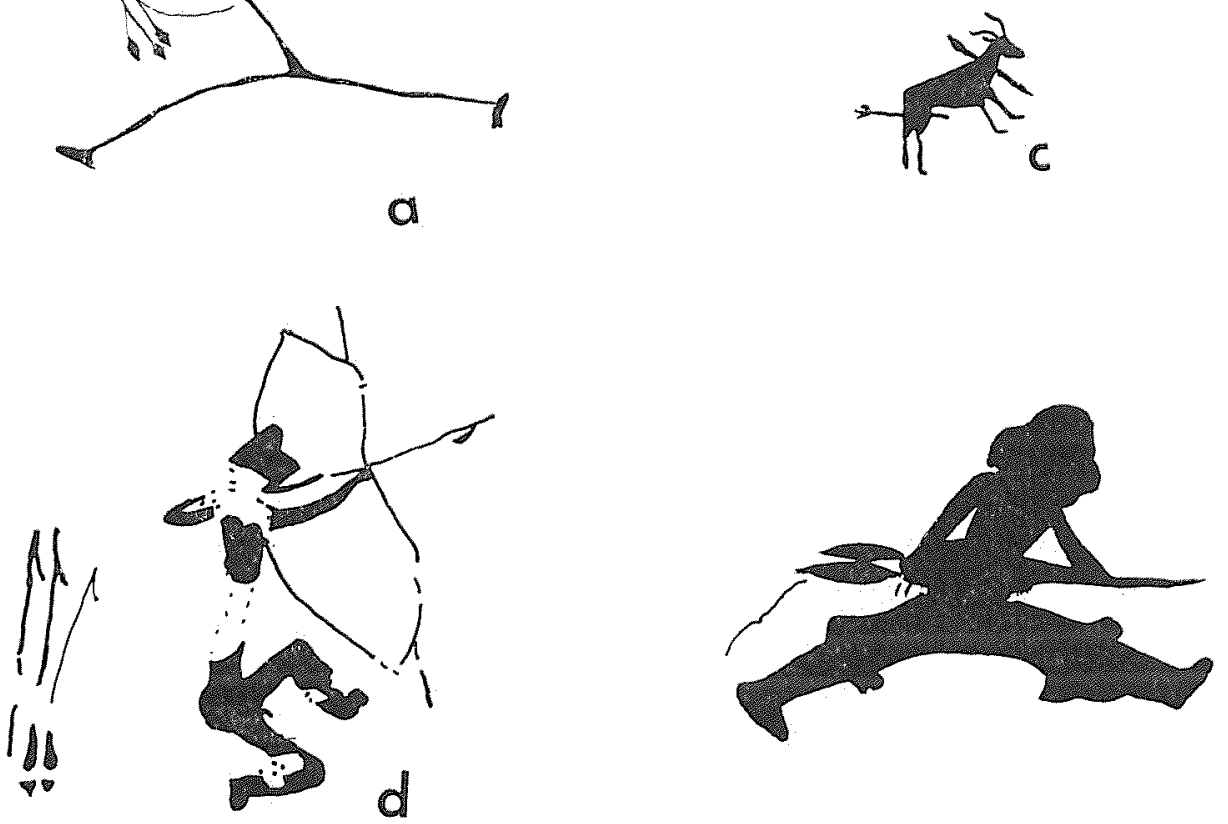

LAMINA IX

Distintos tipos de flechas: a) de emplumadura lanceolada, $b$ y $c$ ) de emplumadura de trazos transversales, d) con la punta doblada en ángulo agudo, e) arma arrojadiza, interpretada por Almagro como posible jabalina, aunque quizá sean dos flechas.

(34) Lhote, Henri: Sur les rapports entre les cendres d'art prehistorique d'Europe (Province franco-cantabrique et Levant espagnol) et celui du Sahara. En «Prehistoric Art of the Western Mediterranean and the Sahara». Chicago, 1964, pág. 218. 
El arco de curva múltiple, aunque con menor frecuencia, aparece también representado en el Arte Levantino y exclusivamente en la Cueva de la Vieja de Alpera y en Minateda, abrigos en los que, como hemos dicho antes, abunda el de triple curva, por lo que pensamos que ambas variedades están íntimamente relacionadas.

El arco formado por dos segmentos lo encontramos sólo en diez ocasiones, aunque geográficamente está mucho más extendido que el arco múltiple, pues aparece no sólo en los abrigos más meridionales. sino también en el Barranco de la Valltorta (Castellón) (lámina VIII d).

En cuanto a las flechas, podemos hacer también una diferenciación formal atendiendo a sus dos extremos: punta y emplumadura. Esta tiene normalmente forma lanceolada, como puede verse con toda claridad en los abrigos del Barranco de la Valltorta (lámina IX a), no obstante. cuando son muy pequeñas sólo es perceptible un abultamiento del que no puede determinarse su forma; en algún caso la emplumadura consta de varios apéndices colocados alerededor del vástago y que parecen estar hechos con plumas (lámina IX $\mathrm{b}$ y $\mathrm{c}$ ).

El extremo contrario, es decir, la punta, suele estar simplemente aguzada, aunque no es raro el que se presente doblada, formando un ángulo agudo (abrigos del Ciervo, Galería del Roure, Tortosilla, La Araña, el Cingle, La Vieja y Minateda) (lámina IX d).

Con respecto a las otras armas arrojadizas resulta imposible establecer una clasificación, puesto que se trata siempre de representaciones muy problemáticas. Baste citar aquí que ha sido señalada la presencia de jabalinas en Val del Charco del Agua Amargo, Galería Alta del Roure y Cueva del Tío Garroso; en esta última Almagro ha interpretado como tal una especie de venablo aguzado que se duplica y termina en dos hojas lanceoladas de punta bífica, con una cuerda colgando de cada una de ellas (lámina IX e).

Por su parte, Vilaseca indica la presencia, en la cueva del Polvorín, de un palo que tiene en un extremo un arco cerrado y alargado que constituye un posible arpón. Igualmente problemáticas son las representaciones del Covacho Ahumado del Moretero y del Cingle de La Mola Remigia, identificadas como azagayas, así como las posibles palmetas reproducidas en Minateda y en los Borriquillos y el objeto interpretado como una pértiga, existente en el Cingle de La Mola Remigia. También se ha hablado de lanzas, mazas y piedras, aunque siempre con bastantes reservas.

Queda mencionar el arma cortante que lleva un personaje del Cingle 
de la Mola Remigia, el cual está en actitud de «descabellar» a un animal, la cual, por su forma triangular, podría tratarse de un puñal.

b) Recipientes: Aunque es normal que los cazadores sostengan sus armas directamente en la mano, hay que hacer constar la indiscutible representación de carcajes en dos abrigos: la cueva Saltadora y la cueva Remigia. En el primero aparece el recipiente aislado de otras figuras, como depositado en el suelo y cargado de flechas cuyas emplumaduras sobresalen (lámina X a); en la cueva Remigia es transportado por uno de los cazadores de jabalíes, e igualmente son visibles parte de las flechas (lámina $\mathrm{X}$ b). Con mayor reserva hay que aceptar el carcaj que lleva a la espalda un cazador de ciervos de El Polvorín o el que sostiene con la mano uno de los arqueros del Civil.
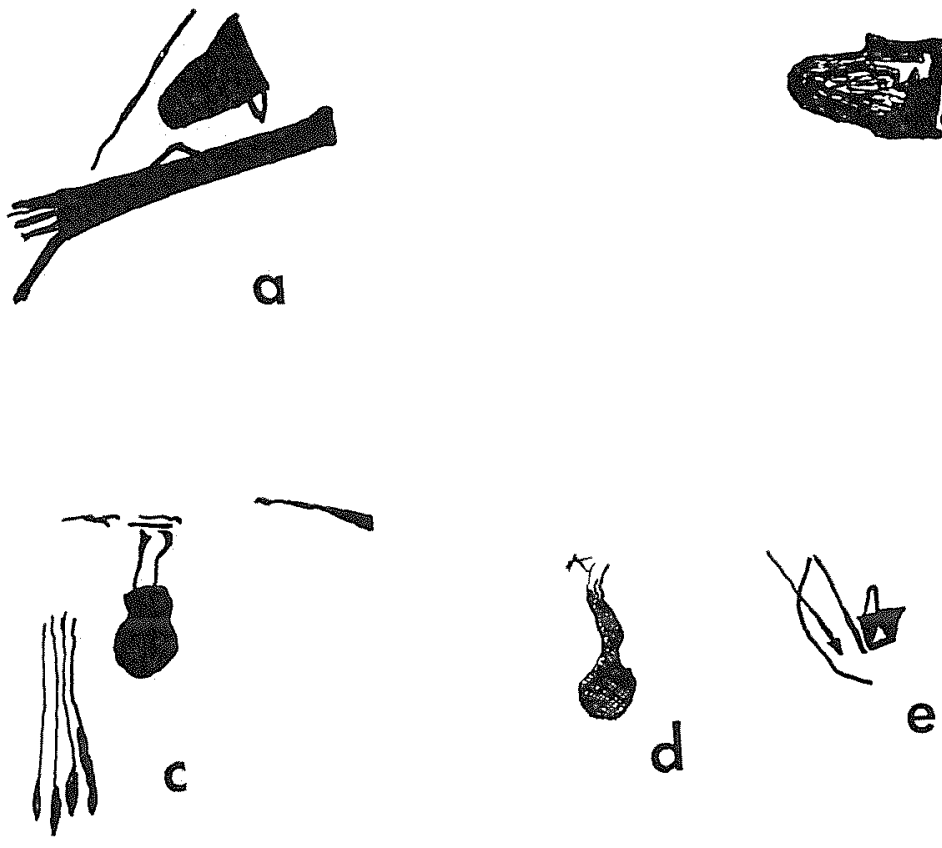

e

LAMINA $\mathrm{X}$
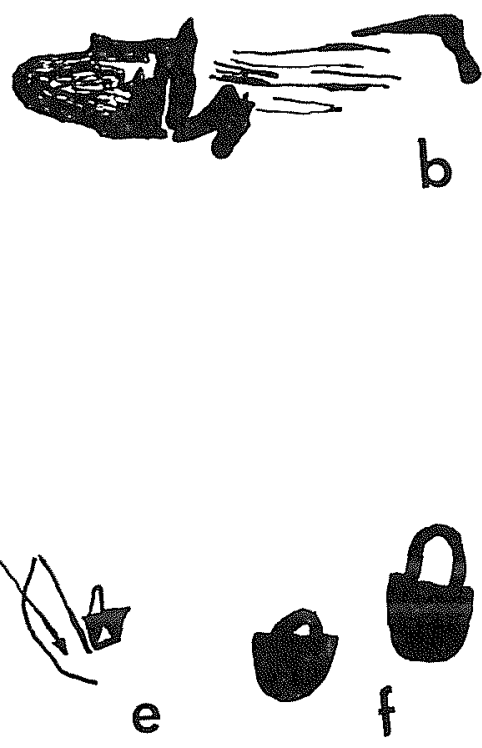

Distintos tipos de recipientes: $a$ y $b$ ) Carcajs. $b, c, d, e$ y f) Cesto.

Indudable es también la utilización de otro tipo de recipientes: cestos o cubos, cuya finalidad no es tan clara, aunque se ha llegado a decir que «quizá no sea muy casual la presencia de figuras humanas, portadoras de vasijas entre los grupos de hombres armados, estando proba- 
blemente en relación directa con ellos, como distribuidores de líquidos (venenos o colores)» (35). Si aceptamos la posibilidad de la utilización de venenos, los recursos de la caza de aquellas gentes se verían sensiblemente acrecentados.

En algún caso vemos estos recipientes abandonados en el suelo (La Saltadora y Val del Charco), e incluso en ocasiones parecen haber sido intencionadamente escondidos en una grieta del terreno, como es el caso del Cingle de la Mola Remigia.

Tanto los carcajes como los otros recipientes son de diferentes formas; aquellos presentan aspecto bien de cilindro muy estrecho, bien de cono con el extremo redondeado. Los «cestos» pueden ser: semiesféricos, esféricos, trapezoidales, triangulares, etc., estando provistos normalmente de una gran asa colocada en la parte superior o de una más pequeña situada en uno de los laterales (lámina $\mathrm{X}$, figuras $\mathrm{b}, \mathrm{c}$, d, e y f).

Aunque no se puede conocer la materia con la que estuvieron confeccionados, el hecho de que un recipiente existente en la cuva Remigia tenga en el interior una serie de líneas entrecruzadas (lámina X d), parece indicarnos un trabajo de cestería, pero no se puede descartar la posibilidad del empleo de cuero en algunas ocasiones.

c) Trampas y Lazos: Además de la posible trampa representada en el Abrigo del Ciervo del Barranco de Dos Aguas, de la que ya hemos hablado, existen en la cueva de La Vieja de Alpera una especie de tectiformes rectangulares rellenos con líneas paralelas en el interior, semejantes a los signos del arte cuaternario (36), pintados junto a las patas de algunos ciervos, lo que nos hace pensar que, al igual que en la pintura paleolítica representan trampas.

En el Cinto de la Ventana del mismo Barranco de Dos Aguas hay además unos trazos muy confusos pintados junto a unas ¿figuras aladas?, que Jordá ha interpretado como posible «trampa de pájaros», pero tal hipótesis hay que aceptarla con muchas reservas dado lo fragmentario de su conservación (lámina VII b).

Por otra parte, en el Covacho Ahumado del Barranco del Mortero hay «dos cabezas gemelas de las que arranca un trazo prolongado, que podría representar el tronco de un árbol utilizado como ¿barrera o tram-

(35) Obermaier y Wernert, 17. Pág. 112.

(36) Casado, Pilar: Tipología de los «signos» en el arte parietal paleolitico de la Peninsula Ibérica. «Actas del XII Congreso Nacional de Arqueología». Zaragoza, 1973, pág. 68, fig. 1-II. 
pa?» (37); pero desgraciadamente, como en tantas otras ocasiones, se trata de figuras muy problemáticas de las que cualquier interpretación resulta aventurada.

Si no existen pruebas claras para certificar con seguridad a través de las pinturas que aquellas gentes utilizaron trampas, sí tenemos testimonios evidentes del empleo de lazos en la caza de un équido representada en el Abrigo de Selva Pascuala y en la cueva del Polvorín, donde un arquero lo ha empleado para aprisionar una cierva, aunque no puede destacarse la hipótesis de que sea utilizado para mantener atadas a las presas capturadas vivas. A estos dos ejemplos claros cabe añadir otros tres casos no tan evidentes representado en la cueva de la Araña.

\section{OPERACIONES DE LA CAZA}

Aunque en parte ha quedado dicho ya, faltan alguno detalles que son posibles reconstruir a partir de escenas representadas sobre diferentes abrigos, las cuales nos permiten conocer un panorama bastante exacto de las diferentes fases y circunstancias de la caza.

En primer lugar, es preciso señalar que el sujeto de la caza fue exclusivamente el hombre, ya que en ningún caso aparecen mujeres relacionadas con esta actividad (38). Los cazadores acudían a su trabajo portando ellos mismos las armas que, sólo en casos excepcionales, transportaban dentro de recipientes, incluso normalmente disparaban sujetando con la mano que sostenía el arco todo el haz de flechas.

Si la caza se practicaba individualmente, parece que se efectuaba, en primer lugar, una operación de rastreo siguiendo las huellas de los animales, tal como se desprende de siete escenas de la Cueva Remigia y de otros casos aislados representados en el Cingle, en la Cueva dells Tolls y en la Galería Alta de Morella, pues aunque en ocasiones es posible que lo que se haya querido representar sean los cazadores siguiendo el rastro de sangre de un animal herido, en otros casos, el hecho de que se hayan pintado los trazos a pares, parece indicarnos que se trata de las huellas dejadas por las pisadas de un cuadrúpedo (lámina XI). Una vez encontrada la presa, debían enfrentarse abiertamente sin ningún tipo de defensa, disparando contra ella un número variable de flechas, hasta dejarla malherida; no obstante, más de una vez debieron ser

(37) Ortego, Teógenes, 10. Pág. 19.

(38) Hernández-Pacheco, Eduardo, 12. Págs. 66-67. 
atacados por los animales, como parece desprenderse de varias escenas de las que hemos hablado. Sólo en casos aislados y para los équidos se utilizaban lazos, con lo que se evitaba el enfrentamiento directo con el animal.
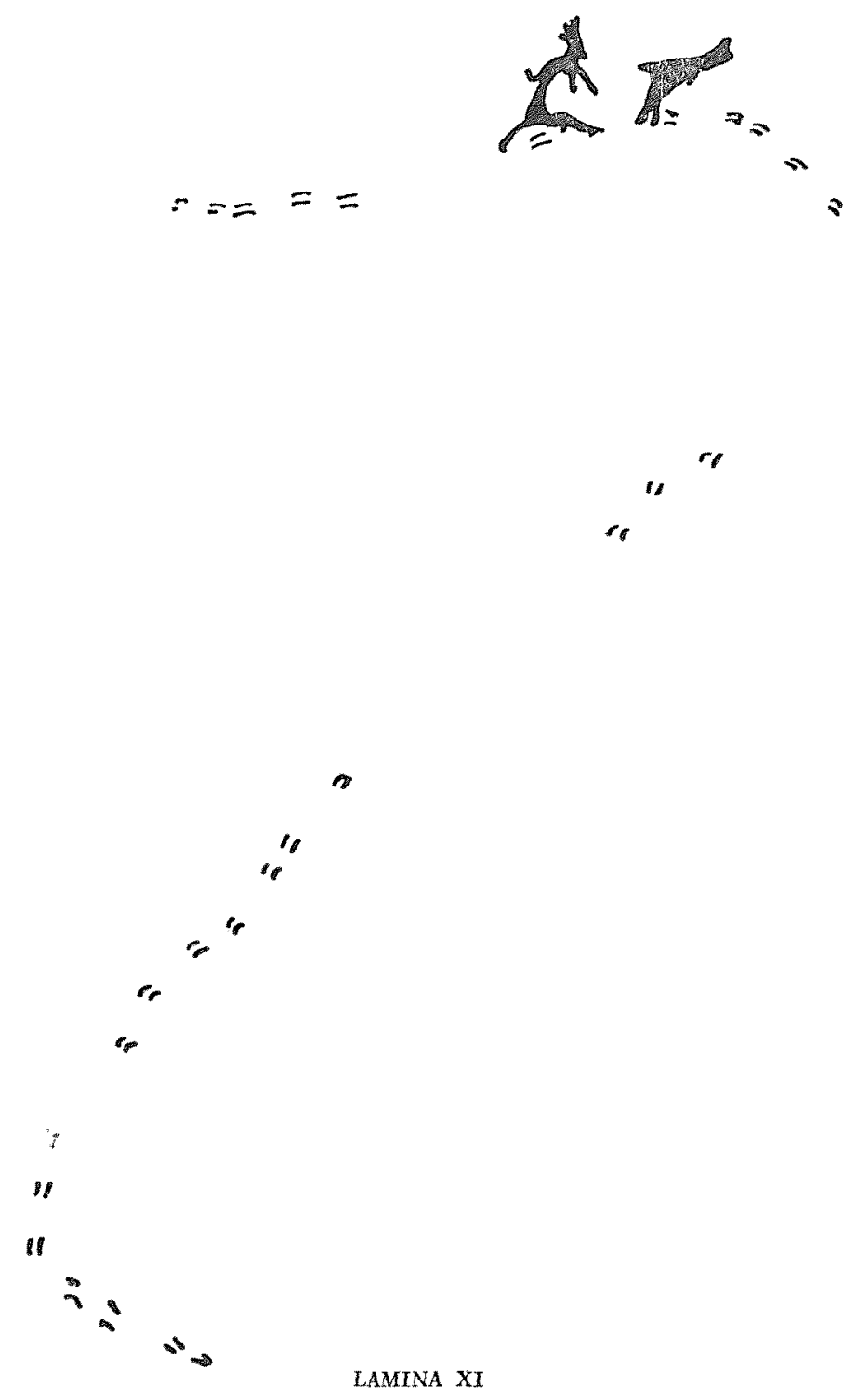

Cazador siguiendo las huellas de un animal. Galería Alta de Morella (según J. B. Porcar). 
Cuando la pieza era aprisionada sin estar totalmente muerta, debía de practicársele una especie de "escabello» in situ, como puede deducirse de una escena del Cingle de la Mola Remigia.

El transporte de las piezas no está representado con nitidez en ninguna escena, pues sólo existen dos representaciones muy confusas que no son suficientes para llegar a conclusiones seguras. Posiblemente, si los animales eran de gran tamaño serían transportados por varios cazadores, o por uno solo en el caso de que fueran piezas pequeñas, según se desprende de una confusa figura del Cingle en la que un personaje parece llevar sobre los hombros, transversalmente a su cuerpo una carga, posiblemente atada con correas o cuerdas y que cabe interpretar como un animal ya que a uno de los lados cuelga lo que parece una larga cola (39).

No obstante, en una representación de la Cueva Remigia hay, «al parecer, un animal colgado de cuatro palos, dos verticales y dos horizontales» (40), que cabría interpretar como un sistema de transportar las piezas cobradas en la caza, pero la poca claridad de la figura - por otra parte única en su género- nos obliga a aventurar esta idea como mera hipótesis.

En lo que respecta a las cacerías colectivas, sólo tenemos escenas completas de capturas de cápridos y de cérvidos y en ambos casos parece que se practicaba el sistema del ojeo; para ello, un grupo de arqueros perseguía a la manada disparando dardos contra los animales y dirigiéndolos hacia un lugar concreto, posiblemente un paso estrecho, donde estaba apostado otro grupo de cazadores que les cerraban el paso, rodeando totalmente a sus presas, generalmente ya heridas por los disparos de sus perseguidores. Parece que para el cerco de las piezas no se utilizaba el fuego, pero sí es posible que en algún caso la muerte de los animales no fuese provocada por los disparos de los cazadores, sino que fuesen obligadas a dirigirse a un barranco donde se despeñarían, como cabe deducirse de la posición de una cierva representada en el Abrigo de los Toros de Tormón y del gran équido de la Cueva de la Araña, los cuales parecen estar cayendo en el vacío, con la cabeza y las patas delanteras hacia abajo, aunque en ambos casos se trata de animales sin relación con otras figuras.

(39) Ripoll, Eduardo, 16. Pág. 35.

(40) Porcar, J. B.; Obermaier, H., y Breuil, H., 27. Pág. 27. 


\section{CONCLUSIONES}

Aunque el mal estado de conservación de muchos de los frisos con pinturas rupestres levantinas nos impide conocer datos importantes que, sin duda fueron representados, es posible, dado el estado actual de los conocimientos, reconstruir una buena parte de las características circunstancias de la actividad cinegética de las gentes que las crearon, la cual constituyó indudablemente su quehacer fundamental. Así hemos podido llegar a deducir que:

a) Las especies más cazadas fueron los cápridos y los cérvidos.

b) Se obtenían además otros tipos de animales, como jabalíes, bóvidos y équidos, aunque en mucha menos proporción que los anteriormente citados.

c) El armamento básico lo constituía el arco y la flecha, empleándose no sólo el arco simple, sino también el compuesto o reflejo de mayor efectividad.

d) En algunos casos se utilizaron lazos y es posible que se sirvieran también de trampas, aunque las representaciones de éstas no son muy claras.

e) Parece que el empleo de tocados en forma de cabezas de animales se debe más a un ardid de caza que a una finalidad meramente ornamental.

f) Aunque lo más frecuente son representaciones de caza individual, no faltan las cacerías en las que se empleaba el sistema del ojeo.

g) El rastreo de las piezas debía hacerse por medio de la observación de las huellas de los animales.

h) No existen representaciones suficientemente claras para conocer el sistema que se utilizaba para recobrar la pieza, para asegurar su muerte o para su transporte. 